Herz 2019 · 44:363

https://doi.org/10.1007/s00059-017-4651-5

Received: 16 October 2017

Accepted: 12 November 2017

Published online: 5 December 2017

(c) Springer Medizin Verlag GmbH, ein Teil von Springer Nature 2017

F. M. Uçar

Department of Cardiology, Trakya University Hospital, Edirne, Turkey

\title{
The implantable cardiac monitor and pocket infection
}

To the Editor,

Lauschke et al. [1] reported that a newly developed implantable cardiac monitor (ICM; BioMonitor) effectively detects patients with cardiac arrhythmia. In this prospective nonrandomized study, the BioMonitor provided safety results within the expected range. The implantation was successful in all 152 patients, and two device-related serious adverse events (pocket infections) occurred at 3 months.

Cardiac implantable electronic devices (CIEDs) mainly include pacemakers, implantable cardiac defibrillators (ICDs), and cardiac resynchronization therapy (CRT) devices. ICMs can also be added to this list. Previous trials reported that the incidence of CIEDrelated infections ranges from 0 to $12.6 \%$ $[2,3]$. Pocket infections prolong hospital stay and increase medical costs. Moreover, the increased incidence of infectious complications is associated with substantially elevated morbidity and mortality rates $[4,5]$. In this study, devices were implanted epifascially in $42 \%$ of the patients and subcutaneously in $52 \%$. Although ICM implantation is regarded a simple process, the infection range was $1.3 \%$.

In this well-presented article by Lauschke and colleagues, two devicerelated serious adverse events (pocket infections) occurred by 3 months in two patients and the devices were explanted. No additional data are provided about these two patients. There are various host-related and procedurerelated factors associated with CIED infections, including diabetes mellitus, chronic obstructive pulmonary disease, corticosteroid use, renal insufficiency, malignancy, heart failure, preprocedural fever, anticoagulant drug use, skin disorders, postoperative hematoma, and lack of antibiotic prophylaxis [6]. In light of this knowledge, it might be beneficial to know the baseline characteristics of these patients so as to avoid ICM infection.

\section{Corresponding address}

\section{F. M. Uçar}

Department of Cardiology, Trakya University

Hospital

Edirne, Turkey

dr_fmucar@hotmail.com

Conflict of interest F. Mehmet declares that he/she has no competing interests.

\section{References}

1. Lauschke J, Busch M, Haverkamp W et al (2017) New implantable cardiac monitor with threelead ECG and activenoise detection. Herz 42:585-592

2. Cabell CH, Heidenreich PA, Chu VH et al (2004) Increasing rates of cardiac device infections among medicare beneficiaries: 1990-1999. Am Heart J 147(4):582-586. https://doi.org/10.1016/j.ahj. 2003.06.005

3. Chua JD, Wilkoff BL, Lee let al (2000) Diagnosis and management of infections involving implantable electrophysiologic cardiac devices. Ann Intern Med 133(8):604-608. https://doi.org/10.7326/ 0003-4819-133-8-200010170-00011

4. Ra'Ad T, Elena D, Kasra M et al (2016) Inhospital mortality among patients receiving an implantable cardioverter-defibrillator in the United States: 2000 to 2012. J Am Coll Cardiol 67(13):862. https://doi.org/10.1016/S07351097(16)30863-4

5. PatriciaK, Steven P(2001) Implantablecardioverter defibrillator complications: infection, erosion, thrombosis. Card Electrophysiol Rev 5(1):110-114

6. Polyzos KA, Konstantelias AA, Falagas ME (2015) Risk factors for cardiac implantable electronic device infection: a systematic review and metaanalysis. Europace 17:767-777 